Ensino, Saúde e Ambiente-V5 (2), pp. 282-293, ago. 2012

\title{
ENSINO INTRADISCIPLINAR NA BIOLOGIA: REFLEXÕES DE UMA INTERVENÇÃO NA TERCEIRA SÉRIE DO ENSINO MÉDIO
}

\section{INTRADISCIPLINARY TEACHING IN BIOLOGY: REFLECTIONS OF AN INTERVENTION IN THE THIRD SERIES OF HIGH SCHOOL}

\author{
Carlos Alberto Vasconcelos Freitas ${ }^{1}$, Valéria da Silva Trajano ${ }^{2}$, Elizabeth Ferreira \\ Rangel $^{3}$, Claudia Mara Lara Melo Coutinho ${ }^{4}$
}

\footnotetext{
${ }^{1}$ Laboratório de Transmissores de Leishmanioses - LTL, Instituto Oswaldo Cruz - IOC, Rio de Janeiro, RJ; Secretaria de Estado de Educação do Estado do Rio de Janeiro - Colégio Estadual Almirante Frontin, cfreitas@ioc.fiocruz.br

${ }^{2}$ Laboratório de Inovações em Terapias, Ensino e Bioprodutos - LITEB, Instituto Oswaldo Cruz - IOC, Rio de Janeiro, RJ, trajano@ioc.fiocruz.br

${ }^{3}$ Laboratório de transmissores de Leishmanioses - LTL, Instituto Oswaldo Cruz - IOC, Rio de Janeiro, RJ, efrangel@ioc.fiocruz.br

${ }^{4}$ Laboratório de Inovações em Terapias, Ensino e Bioprodutos - LITEB, Instituto Oswaldo Cruz - IOC, Rio de Janeiro, RJ; Departamento de Biologia Celular e Molecular, Instituto de Biologia, Universidade Federal Fluminense - UFF, Niterói, RJ, ccoutinho@ioc.fiocruz.br
}

\begin{abstract}
RESUMO
Este trabalho analisa uma proposta de ensino de biologia, promovendo a integração de conteúdos: ambiente (aspectos biossocioambientais), citologia, histologia, anatomia e fisiologia. Para isso foi desenvolvido um projeto temático intitulado 'Doença: decifrando este enigma' para o qual foi elaborado um plano de ensino que buscou coadunar os conhecimentos da patologia geral como elementos dinamizadores dessa integralização. A fundamentação teórica esta centrada na abordagem relacional e no pensamento de Paulo Freire. A realização da atividade mostrou como resultado que é possível desenvolver um trabalho intradisciplinar no ensino de biologia, porém com algumas dificuldades, dentre elas a cultura escolar das aulas de biologia, que, por vezes, deixa de lado essa questão. Este trabalho refere-se a uma pesquisa de mestrado profissional em Ensino de Biociências e Saúde com uma turma de $3^{\mathrm{a}}$ série do ensino médio da rede pública de ensino do Estado do Rio de Janeiro.
\end{abstract}

Palavras-chave: projeto temático, intradisciplinaridade, doença, biologia

\begin{abstract}
This paper examines a proposal for teaching biology by promoting the integration of content: environment (aspects biossocioambientais), cytology, histology, anatomy and physiology. For this it was developed a thematic project titled 'Disease: deciphering this puzzle' for which was prepared a teaching plan which sought to harmonize the knowledge the general pathology as the enablers of this integralization. The theoretical basis is centered on the approach relational and in the thought of Paulo Freire. The performance of activity as the main result showed that it is possible to develop a work intradisciplinary in the biology education, but with some difficulties, among them the culture of biology classes, which sometimes leaves out the question. This work refers to a master thesis professionalizing in the Teaching of Bioscience and Health with a class of $3^{\text {rd }}$ grade of high school the public school system of the State of Rio de Janeiro.
\end{abstract}

Key words: thematic projetic, intradisciplinarity, disease, biology 


\section{INTRODUÇÃO}

O presente trabalho sintetiza os resultados de uma pesquisa científica realizada como trabalho de conclusão do curso de pós-graduação em Ensino de Biociências e Saúde do Instituto Oswaldo Cruz. O mestrado profissionalizante como espaço de pesquisa e construção do conhecimento foi cenário para a pesquisa realizada numa escola pública do Estado do Rio de Janeiro.

A intervenção didática teve por objetivo a promoção da intradisciplinaridade, isto é, viabilizar a percepção integrada dos eventos ambientais e biológicos a partir de um tema gerador de uma situação-problema. A partir da situação-problema 'doença', enquanto fenômeno biossocioambiental, foi elaborado um plano de ensino, substanciado na abordagem relacional, com foco na integração de conteúdos como: ambiente e seus aspectos biossocioambientais (agentes químicos, físicos, biológicos e sociais), citologia, histologia, anatomia e fisiologia. O tema gerador originou o titulo do projeto temático "Doença: decifrando este enigma" para o qual foi elaborado o plano de ensino que buscou coadunar os conhecimentos da patologia geral como elementos dinamizadores dessa integralização.

O projeto temático 'Doença: decifrando este enigma' foi aplicado numa turma, constituída por 32 (trinta e dois) alunos, da terceira série do ensino médio da rede pública. Aconteceu no horário destinado ao desenvolvimento de projeto (atividade complementar), instituído na parte diversificada da grade curricular do ensino básico da rede estadual. Foi desenvolvido durante o período letivo de 2008 totalizando 60 (sessenta) horas / aula.

Os resultados da pesquisa mostram que é possível o processo de ensino intradisciplinar na biologia, esse processo compreende mudança de postura em sala de aula de professores e alunos, porém é necessário um planejamento bem elaborado.

Apresentamos nas seções a seguir, de forma sucinta, parte da fundamentação teórica utilizada no planejamento, execução e análise das atividades de ensino. Os aspectos metodológicos da pesquisa e uma discussão dos resultados da pesquisa.

\section{DELINEAMENTO TEÓRICO-METODOLÓGICO DO PROCESSO DE ENSINO APLICADO EM SALA DE AULA}

Ao observarmos a sequência dos conteúdos programáticos lecionados no ensino médio constatamos um processo de escolarização bancário sustentado na aplicação da 'lógica factual' na transmissão do conhecimento para o ensino. O conteúdo 
biológico é apresentado ao estudante como um fato científico cuja conexão com os demais fatos segue um raciocínio ascendente, isto é, de uma dimensão micro a uma dimensão macro dos conhecimentos biológicos. Essa prática propedêutica privilegia o sequenciamento expositivo-explicativo de conteúdos, ocasionando a fragmentação do conhecimento.

Segundo Krasilchik (2005, p. 50) essa é uma situação recorrente no ensino dos conteúdos de biologia...

[...] a falta de integração intradisciplinar é fonte de grandes dificuldades no aprendizado de biologia. O conteúdo é apresentado dividido em compartimentos estanques, sem propiciar aos alunos oportunidades de sintetizar e dar coerência ao conjunto, o que seria possivel se lhes fossem mostradas as ligações entre fatos, fenômenos, conceitos e processos aprendidos. Por exemplo, [...] Citologia é um segmento do curso que se encerra em si mesmo, sem que, ao analisar a fisiologia no nível de organização do indivíduo, os alunos tenham oportunidade de voltar a considerar o fenômeno no nível celular.

Com o objetivo de proporcionar aos docentes mecanismos de minimizar essa situação a secretaria estadual de educação disponibilizou o planejamento do currículo mínimo para todas as disciplinas do ensino básico. O currículo mínimo planejado e elaborado para o ensino de biologia apresenta eixos temáticos nos quais são objetivadas habilidades e competências especificas. Nesse contexto temático amplo há a possibilidade do professor trabalhar temas geradores, complementares e/ou transversais ao eixo temático principal (SEE, 2012). Nesse atual contexto de reestruturação curricular este projeto poderá ser desenvolvido na segunda série como tema gerador, integrador e complementar aos eixos temáticos planejados para esta série.

Projetos temáticos são práticas pedagógicas que promovem a atividade de pesquisa, contextualização e (re)significação de situações-problema e essa modalidade de ensino é eficiente quando o estudante, ao iniciar suas atividades, tem uma visão integrada dos elementos e fenômenos inerentes ao tema em questão. Nesta perspectiva Moraes (2004) propõe a utilização de um esquema relacional. A representação esquemática configura como sendo um dos procedimentos didáticos a ser utilizado na evidenciação do estudo das relações entre os elementos e fenômenos físico-químicos, biológicos, humanos e sociais constituintes da dimensão relacional do objeto de estudo.

Neste sentido a investigação temática pode viabilizar a aplicação da 'lógica relacional' no processo de escolarização. No planejamento dessa atividade didáticopedagógica, Freire (1977) propõe o processo de codificação - problematização decodificação. Situando esse procedimento, no ensino de ciências, Delizoicov e cols 
(2002), descreve os "momentos pedagógicos": a) problematização inicial - estimular o interesse do estudante por assuntos de sua cotidianidade, bem como, por temas gerais da atualidade; b) organização do conhecimento - planejamento didático-pedagógico e sistematização do conhecimento pelo docente; c) aplicação do conhecimento apropriação e articulação do conhecimento pelo aluno de forma que possa aplicá-lo em prática diária de vivência.

A transformação de um tema gerador em situação-problema ocorre quando de sua problematização, isto é, na medida em que se deseja (re)conhecê-lo. Passa a constituir-se, segundo Freire, em uma "situação gnosiológica" (FREIRE, 1977) estimuladora de questionamentos e, portanto, passível de ser conhecida e transformada em conhecimento. Problematizar um tema em sala de aula é uma atividade de cunho gnosiológico e não se confunde, a priori, com buscas de soluções, mas na compreensão analítica de seus determinantes e particularidades, subsidiando intelectualmente o indivíduo no entendimento e na (re)construção de seus caminhos de pensamento.

Constrói-se, em sala de aula, o que Paulo Freire (2006) denomina de "ciclo gnosiológico" que compreende as ações de ensinar, aprender e pesquisar. A didática da problematização proporciona questionamentos sobre o fenômeno em estudo com o intuito de esquadrinhar suas nuances.

No plano de ensino elaborado para o tema Doença: decifrando este enigma as seguintes questões - com suas respostas-objetivo preliminarmente formuladas - foram trabalhadas ao longo de seu desenvolvimento:

a) Biologicamente, o que significa estar doente? Tencionou-se a compreensão de doença como um fenômeno biológico acontecendo em nível orgânico; passível de explicação a partir do entendimento do funcionamento morfofisiológico do organismo e da interação que mantemos com os fatores bióticos, abióticos e sociais do meio no qual estamos continuamente ou temporariamente inseridos.

b) O que acontece dentro do organismo humano nos níveis de células e tecidos, por exemplo, quando sofremos alguma agressão (química, física, biológica, social)?

A ideia principal do plano de ensino foi demonstrar a 'lógica relacional' da cinética de eventos biossocioambientais, proporcionando a interconexão de conteúdos no entendimento dos eventos biológicos, resultantes de agressões, acontecendo no organismo humano e que são comuns a diferentes tipos de doenças:

É necessário imaginar um órgão teórico, representado por uma porção parenquimatosa, cujas células são de origem ecto elou endodérmica, [...], cercada por tecido conjuntivo vascular, mesenquimal, que serve como 
seu suporte, nutrição e defesa. Deve-se sempre imaginar que, ao lado da microcirculação, [...], existe o conjunto de linfáticos. [...] relacionado a um nódulo linfático. Imaginemos agora agressões de intensidades diversas que se fazem sentir sobre este órgão. [...] quando leve, pode atingir apenas a membrana celular [...] interferindo principalmente nos mecanismos de troca das células com o meio ambiente. [...] predominantemente nas vias de metabolismo celular, [...], o que se manifesta morfologicamente através da retenção de determinadas substâncias, tais como ácidos graxos ou através de alteração da bomba de sódio com acúmulos anormais de sódio e potássio intra e extracelulares. Finalmente é possível que a lesão seja de tal intensidade que leve à morte de grupos de células. Desde que esta não atinja [...] a viabilidade do órgão como um todo [...] a resposta a essa agressão se fará através [...] do processo inflamatório. A eliminação do agente lesivo determina o término da reação inflamatória, [...], e põe em ação os processos de reparação (BRITO, 1995, p.249-253).

c) $\mathrm{O}$ que fazemos e a que estamos expostos em nosso cotidiano que resultam em distúrbios orgânicos? Todos os aspectos delineados acima devem ser vistos numa perspectiva relacional. Estamos no ambiente e somos 'ambiente' também. Isto é, o meio só se constitui em ambiente quando nele há organismos. Portanto, o termo ambiente expressa a ideia de interação entre meio e organismos (LEWONTIN, 2002).

Somos, portanto, organismos que além de inseridos em uma realidade ambiental, apresentamos também uma realidade social e histórica que praticamente norteia nossa (co)existência. O discernimento da dimensão relacional na qual (co)existimos e interagimos pode resultar em condições de morbidade ou saúde.

A representação esquemática abaixo (FIGURA 1) busca a visualização das relações biossocioambientais tratadas no contexto desse plano de ensino.

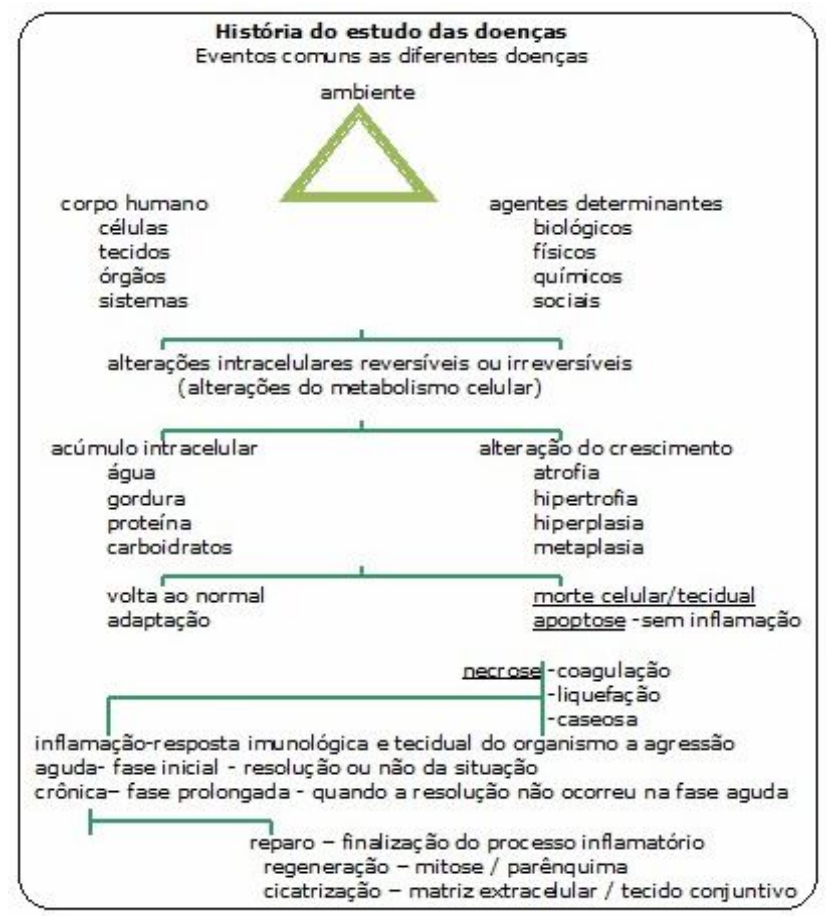

Figura 1. - Proposta de esquema relacional (conteúdos). 


\section{ASPECTOS METODOLÓGICOS}

A questão de pesquisa que norteou a investigação foi: É possível viabilizar a compreensão dos mecanismos biológicos gerais das doenças, a estudantes da terceira série do ensino médio, por meio de um plano de ensino-aprendizagem sob a ótica da abordagem relacional?

O objetivo geral da pesquisa foi desenvolver uma proposta de ensino de biologia intradisciplinar, tendo como foco a compreensão biossocioambiental do fenômeno 'doença'. E para isso foi utilizado o conhecimento básico da patologia geral interagindo com os conteúdos lecionados na disciplina biologia na demonstração da cinética ambiental e morfofisiológica dos eventos biológicos na aparição do estado de enfermidade.

A pesquisa foi organizada em três fases interligadas: 1) aplicação de uma questão aberta para identificar as percepções iniciais dos alunos sobre o que ocorre no organismo humano (nas células, tecidos, órgãos e sistemas) em decorrência das doenças, valorizando o sentido usual que os termos doença e saúde têm para a maioria das pessoas, evitando assim, uma interpretação conteudista da questão:

Por experiência própria cada um de nós sabe o que é estar doente ou sadio; sabe o que é sentir-se bem ou mal em diversas situações. Já ouvimos falar de muitas doenças, como evitá-las e dos procedimentos médicos aos quais devemos nos submeter para 'tratá-las'. É comum ouvirmos também comentários acerca do que ocorre no corpo de uma pessoa quando ela está com alguma enfermidade. Desenvolvendo livremente seu pensamento, fale sobre o que você acha que ocorre no organismo humano (células, tecidos, órgãos e sistemas) em decorrência das doenças.

2) elaboração e aplicação de um plano de ensino sobre o fenômeno doença, na perspectiva da abordagem relacional. O plano apresentou os seguintes itens:

1) Situação-problema: Doença; 2) Objetivos de ensino-aprendizagem; 3) Modalidades didáticas; 3) Clientela; 4) Conhecimentos prévios; 5) Atividades prévias; 6) Conteúdos; 7) Meios de Ensino; 8) Atividades durante o processo de pesquisa; 9) Dinâmica da atividade; 10) Atividade final.

3) aplicação de uma questão aberta para verificar as possíveis informações adquiridas pelos estudantes por meio desse plano de ensino-aprendizagem:

Durante o desenvolvimento de nosso projeto 'doença: decifrando este enigma' descobrimos que existem eventos biológicos que são comuns as diferentes doenças. Desenvolvendo livremente seu pensamento, a luz do que estudamos, decifre este enigma: doença.

Neste sentido a investigação teve desde sua concepção um caráter de pesquisa qualitativa. A ênfase do trabalho é nos processos e não somente nos resultados, cuja contribuição foi a mobilização, por meio de um processo de intervenção didática, da 
participação efetiva e interativa dos sujeitos da pesquisa - professor e alunos - na (re)construção do conhecimento em sala de aula.

A categorização é um procedimento factível de ser utilizado em análise qualitativa (GOMES, 2002). Os discursos dos estudantes foram organizados de forma comparativa. Neste sentido a análise das falas dos estudantes apresenta duas categorias: a primeira refere-se às respostas a primeira questão e na segunda está às respostas a segunda questão; formando o que denominamos de 'categorias discursivas'. Foram elaborados sete pares de categorias discursivas segundo a similaridade dos discursos: sinais e sintomas \& processos biológicos; sinais e sintomas \& sinais e sintomas; sinais e sintomas \& importância do estudo das doenças; processos biológicos \& processos biológicos; processos biológicos \& importância do estudo das doenças; processos biológicos \& vetor; prevenção \& prevenção. Esta análise possibilitou a avaliação do tema proposto e possíveis (re)planejamentos dessa articulação de ensino.

\section{DISCUSSÃO DOS RESULTADOS}

No desenvolvimento de nossa proposta em sala de aula observamos que o tema 'doença' tem um forte vínculo com a realidade e a vivência experiencial do aluno.

Quando do início de nosso projeto os estudantes não tinham a noção de que independente da denominação da doença todo processo biológico que a desencadeia é praticamente o mesmo. No entanto, ao longo do desenvolvimento do projeto, a maioria dos estudantes, começou a perceber que estas disfunções - celulares/teciduais/orgânicas que ocorrem em face de uma agressão são basicamente as mesmas. Começaram a perceber também que o organismo reage praticamente da mesma forma a essas agressões. Mesmo assim observa-se, na maioria dos discursos, a necessidade de uma denominação e manifestações especificas para o estado de enfermidade, evidenciandose a forte concepção de doença como sendo uma expressão social e médica.

Evidencia-se na fala dos alunos o estado de saúde e doença como "metáfora" para explicação dos fatos que ocorrem no meio social no qual habitam, trabalham, transitam, convivem com outras pessoas e, da sociedade de um modo geral. Neste sentido observa-se nos discursos dos alunos o estado saúde-doença como um processo "híbrido biológico-social". No qual a percepção da saúde e da doença é percebida como um fenômeno mais social, sobressaindo-se ao processo biológico (MINAYO, 2006); o que está configurado nos discursos dos estudantes nas descrições de sinais e sintomas. 
Segundo Lefèvre \& Lefèvre (2004), isto ocorre devido ao domínio do conhecimento do processo biológico da doença por especialistas. Esse apoderamento do saber inviabiliza a construção compartilhada do conhecimento entre o saber especializado e o saber de senso comum. Resta ao senso comum à 'informalidade da fala' do saber especializado. Esta situação promove a fragmentação do conhecimento e, por conseguinte, a problemática relacional.

Ao analisarmos as categorias discursivas 'sinais e sintomas \& processos biológicos', 'processos biológicos \& processos biológicos' e 'sinais e sintomas \& sinais e sintomas', observamos que a visão de processo biológico surge em decorrência de disfunções orgânicas ocasionadas por agentes causadores e que é percebida por meio de manifestações de sinais e sintomas. Em algumas dessas respostas há a evidenciação dessas manifestações como uma percepção comum, ou seja, de sentido de visibilidade ou de suposição de estado de doença. Em outras respostas ao citarem as manifestações de sinais e sintomas estabelecem relação de causa e efeito. Há, embora de forma perceptiva, a visualização “de que o corpo humano é depositário de processos biológicos indicadores de saúde ou doença para o indivíduo” (FERREIRA, 1998). Como podemos observar nos discursos dos estudantes:

a) sinais e sintomas \& processos biológicos:

"Quando as pessoas adoecem sentem dores no corpo e muitas vezes sentem febre, isso ocorre como se fosse um aviso de que alguma doença mais grave esta por vir." (aluno 6)

"Quando nossas células sofrem alguma agressão seja pelo meio ambiente químico, biológico ou até mesmo socioeconômico, ela pode até se regenerar, se adaptar ao ambiente ou até morrer. Há inflamação na necrose, depois da inflamação ocorre o reparo que é a regeneração e ou cicatrização." (aluno 6)

b) processos biológicos \& processo biológicos:

"Doenças podem ser causadas por vários fatores que corrompem a harmonia e bom funcionamento das atividades fisiológicas, [...] que atuam de modo diferente em órgãos distintos causando series de complicações $e$ enfermidades reversíveis ou não. Para nos auxiliar nesta guerra microscópica o nosso corpo desenvolveu [...] sistemas imunológicos, que é composto por anticorpos que despertam a qualquer sinal de corpo estranho." (aluno 30)

"Hoje sabemos que as doenças são disfunções biológicas que podem ser causadas por diversos fatores ou agentes, impedindo o bom funcionamento dos órgãos do corpo humano. [...] e ao interagir com o nosso organismo obtém diferentes respostas." (aluno 30)

c) sinais e sintomas \& sinais e sintomas:

"Várias pessoas só sabem que estão doentes quando as coisas se agravam, por exemplo, uma dor de cabeça, febre ou dor no estomago, essas dores é sinal de q alguma parte do organismo não está bem." (aluno 31) 
"A doença é um sintoma indesejável, seria muito bom se não existisse a doença. Ela causa sofrimento não só para o doente, mas também para seus familiares." (aluno 31)

Nestas categorias discursivas observa-se a transição de sinais e sintomas para processo biológico, a exposição e permanência da ideia de processos biológicos e no último caso a ideia de processos biológicos está implícita em suas falas. A percepção de processos biológicos implícitos na descrição de sinais e sintomas, bem como do ambiente influenciando este processo esta relacionada também a vivência experiencial e escolarizada dos indivíduos.

Esses dados demonstram a aplicação da 'lógica factual' do processo de escolarização. Esses estudantes foram submetidos ao longo do ensino básico a um ensino inventariante sobre doenças com seus sinais e sintomas, profilaxias e respectivos agentes causadores. A doença é descrita e apresentada, tanto nos livros didáticos como em sala de aula, como uma 'entidade' que apresenta um conjunto de caracteres que permitem sua identificação (TRAJANO, 2008).

$\mathrm{Na}$ análise dessas categorias discursivas verificamos que os estudantes expuseram suas percepções, as preexistentes e as adquiridas. Reforçando que a abordagem temática possibilita um ambiente de enculturação por meio do desafio de situações-problema. Observa-se que estas categorias representam os discursos em que houve aquisição de novas informações e/ou reorganização do pensamento de senso comum e/ou escolarizado (MORTIMER, 1996).

Estudos antropológicos ajudam a entender essas dimensões dos sinais como sendo as características objetivas e os sintomas como sendo as características subjetivas do estado de doença e suas dimensões relacionais. Neste sentido foram propostos os conceitos de disease, illness e sickness: disease refere-se à doença tal como é entendida pela biomedicina e, obviamente corresponde aos processos biológicos determinantes dos sinais; illness refere-se à percepção do individuo das manifestações desses processos biológicos desenrolando-se em seu organismo caracterizando os sintomas e sickness refere-se a fatores sociais, políticos e econômicos que se encontram na base da determinação social da doença. (KLEINMAN, 1980, YOUNG, 1982, IRIART, 2003).

Helman (2006) relata que caracterizar alguém como doente requer a identificação de manifestações subjetivas e/ou objetivas no estrato físico e/ou psíquico do indivíduo e que sejam socialmente reconhecidos. Tais como: percepção de mudanças na aparência corporal, como peso, mudanças na cor da pele ou queda de cabelo; 
emissões orgânicas incomuns como sangue na urina, no escarro ou nas fezes; mudança no funcionamento de um membro; sintomas físicos desagradáveis, como dor de cabeça, febre ou calafrio; estados emocionais exagerados ou incomuns; etc.

Nesta perspectiva, observa-se que sinais e sintomas constituem-se nos objetos de formulação do "sistema leigo de referência" para o entendimento do fenômeno doença. Constituindo um corpo de conhecimentos experienciais advindos da vivência e da convivência com o estado de doença (ALVES, 2006). Nesse contexto o significado de estar doente é interpretado como um conjunto de sensações e sintomas desagradáveis e/ou impeditivos a normalidade da vida cotidiana (FERREIRA, 1998).

As ideias desenvolvidas de 'estudo do fenômeno doença', 'vetores' e 'prevenção', evidenciam a noção social de saúde e doença. Essas ideias fazem parte da cotidianidade dos indivíduos devido às informações veiculadas nos meios de comunicação sob determinadas circunstancialidades. Essas informações conjuntamente com os conhecimentos experienciais e o vocabulário 'medicalizado' perfazem o imaginário coletivo, de contextos sociais específicos, sobre os estados de saúde e doença (LEFÈVRE \& LEFÈVRE, 2004; ALVES, 1993). Exemplificando:

"Hoje em dia varias doenças estão tendo resultado positivo, como a aids. Já foi descoberto um medicamento que não mata os vírus mas pode bloquear para não mais progredir." (aluno 29) (aluno 3)

"Para mim as doenças podem ser evitadas através das prevenções."

"Entendi que determinadas doenças são transmitidas através de um ser e outras podem ser contraídas através de objetos com bactérias que podem transmitir para outro ser. [...] a dengue é contraída através de um mosquito." (aluno 5)

Esta análise feita por meio da antropologia médica permite-nos afirmar que os estudantes apresentam 'conceitos espontâneos' do que é o estado de doença. Mortimer (2010), analisando os pensamentos de Popper \& Wells e Vygostsk, explica que o conceito deriva de um processo dinâmico denominado conceitualização ou pensamento conceitual; ocorrendo sempre na interação social do individuo com suas experiências externas e dos processos educacionais pelos quais passam. Em Vygostsk, destaca o sentido e o significado das palavras dentro da conceitualização. O sentido são formações dinâmicas, fluidas, complexas e dependendo do contexto a palavra muda de sentido. O significado é construto social relativamente mais estável possibilitando a intersubjetividade, isto é, duas ou mais pessoas podem compartilhar na mesma palavra o mesmo significado, ainda que variem de sentido que atribuem a ela. Nesta perspectiva a palavra é portadora do conceito. 
Correlacionando a esfera educacional com a antropológica: o "sistema leigo de referência" - onde estão inseridas as categorias sinais e sintomas, processos biológicos, vetores, prevenção - situa-se no campo das conceitualizações, ou seja, no campo experiencial, das percepções. É o que verificamos mediante as respostas dos estudantes.

$\mathrm{O}$ fato de alguns estudantes terem citado termos mais específicos, em suas respostas, pode ser indicio de certa apropriação desses termos, mas refletiram uma compreensão conceitual e biológica incipiente. Observa-se isto diante da dificuldade do estabelecimento de correlações entre os conteúdos anteriormente lecionados na disciplina biologia e os conteúdos trabalhados no desenvolvimento do tema; no entanto estes resultados demonstram a viabilidade do prosseguimento do estudo desta ação didático-pedagógica.

\section{REFERÊNCIAS}

ALVES, P. C. A Fenomenologia e as Abordagens Sistêmicas nos Estudos sócioantropológicos da doença: breve revisão crítica. Cadernos de Saúde Pública. Rio de janeiro, 22(8): 15547-1554, ago., 2006.

. A Experiência da Enfermidade: Considerações Teóricas. Cadernos de Saúde Pública. Rio de Janeiro, 9(3): 263-271, jul/set, 1993.

BRITO, T. Visão integrada dos processos patológicos. Em: M.R. Montenegro e M. Franco (Eds.). Patologia Processos Gerais. Rio de Janeiro: Atheneu. 1995. pp. 249253.

DElizoicov, E; ANGOTTI, J. A; PERnAMBuCO, M. M. Ensino de Ciências: fundamentos e métodos. $2^{a}$ edição. São Paulo: Editora Cortez, 2002.

FERREIRA, J. O corpo Sígnico. In: ALVES P. C, MINAYO M. C. S. Saúde e doença: um olhar antropológico. Rio de Janeiro: Editora Fiocruz, 1998. pp. 101-112.

FREIRE, P. Pedagogia do Oprimido. $4^{\text {a }}$ edição. Rio de Janeiro. Editora Paz \& Terra. 1977.

Pedagogia da autonomia. Saberes Necessários a Prática Educativa. Rio de Janeiro. 33 edição. Editora Paz e Terra, 2006.

GOMES, R. A Análise de Dados em Pesquisa Qualitativa. In: MINAYO M. C. S (org) Pesquisa Social: teoria, método e criatividade. Rio de Janeiro: Editora Vozes, 2002.

GOVERNO DO ESTADO DO RIO DE JANEIRO. Secretaria de Estado de Educação. Currículo Mínimo 2012 Ciências e Biologia. Disponível em: http://www.rj.gov.br/web/seeduc/exibeconteudo?article-id=759820

HELMAN, C. Saúde, Cultura e Doença. 4ª edição. Porto Alegre: Artmed, 2003.

IRIART, J. A. B. Concepções e Representações da Saúde e da Doença. Texto didático. Salvador: ISC-UFBA. 2003

KLEINMAN, A. Patients and healers in the context of culture. Berkeley: University of California Press, 1980. Apud IRIART, J. A. B. Concepções e Representações da Saúde e da Doença. Texto didático. Salvador: ISC-UFBA. 2003

KRASILCHIC, M. Prática de Ensino de Biologia. $1^{a}$ edição. São Paulo. Editora Universidade de São Paulo. 2005.

LEFRÈVRE, F. \& LEFRÈVE A. M. C. Promoção da Saúde: negação da negação. Rio de Janeiro. $1^{a}$ edição. Editora Vieira \& Lent, 2004. 
LEWONTIN, R. A Tripla Hélice: gene, organismo e ambiente. São Paulo: Companhia das Letras. 2002.

MINAYO, M. C. S. O Desafio do Conhecimento: pesquisa qualitativa em saúde. $9^{\mathrm{a}}$ edição. Rio de Janeiro: Editora Hucitec, 2006.

MORAES, E. C. Abordagem Relacional: uma estratégia para a educação científica na construção de um conhecimento integrado. In: Atas do IV Encontro Nacional de Pesquisa em Educação em Ciências. Bauru: 2004.

MORTIMER, E. F. Construtivismo, Mudança Conceitual e Ensino de Ciências: Para Onde Vamos? Investigação em Ensino de Ciências, v.1 (1), pp. 20-39, 1996.

SCOTT, P; EL-HANI, C. Bases Teóricas e Epistemológicas da Abordagem dos Perfis Conceituais. VII Encontro Nacional de Pesquisa em Educação em Ciências. Florianópolis, 2009.

TRAJANO, V. S. Identificação e Análise dos Saberes Sobre Parasitoses no Contexto Formal e Não Formal de Ensino. Rio de Janeiro, 2008. [Tese de doutorado] Instituto Oswaldo Cruz - Fundação Oswaldo Cruz.

YOUNG, A. The anthropologies of illness and sickness. Annual Review of Anthroplogy, 11:257-85. Apud IRIART, J.A.B. Concepções e representações da saúde e da doença. Texto didático. Salvador: ISC-UFBA, 2003. 